\title{
Technology of surface runoff purification
}

\author{
Zhanna Govorova ${ }^{*}$, Ekaterina Muraveva, Yulia Isachkina and Vadim Govorov \\ Moscow State University of Civil Engineering, 26, Yaroslavskoe shosse, 129337 Moscow, Russia
}

\begin{abstract}
Surface runoff from urban area is a potential source of pollution of water bodies. Characteristics of rainfall runoff in some cities of Russia and foreign countries are given in the article. Traditional wastewater treatment facilities include the mechanical removal of large items, debris and leaves; sand removal; water clarification in accumulative clarifying tanks; chemical dosing, contact filtration and deep purification in sorption filters. Four technological schemes were analyzed. Conceptual difference of the schemes is using a new construction of accumulative clarifying tanks and different types of filters with inert floating polysterene load (CFPZ-1, CFPZ (CS), AFPZ-4). The investigation results of pilot plant that simulates the purification process of surface runoff in clarifying, sorption and I and II step cartridge filters are given in the article. During the investigation period the water entering the pilot plant had the concentration of suspended solids $-81-180 \mathrm{mg} / \mathrm{L}$, petroleum products $-2-8 \mathrm{mg} / \mathrm{L}, \mathrm{COD}$ $-48-97 \mathrm{mg} / \mathrm{L}$. Analysis of the dynamic of changes in the concentration of suspended solids and petroleum products in previously treated in accumulative clarifying tank water during the filter cycle at each step showed that purification efficiency in polystyrene load layer depends on the type and dose of flocculant, filter rate and duration of filtration. The investigation results were used for the development of recommendations for the intensification of operation of industrial filters and improving technological reliability of surface runoff treatment facilities.
\end{abstract}

\section{Introduction}

Storm water runoff is one of the main sources of pollution of water bodies. Purification of surface water runoff to meet the regulatory requirements before it is discharged into water bodies is an urgent task aimed at environmental pollution prevention. Contamination of storm water runoff entering treatment facilities from urban areas depends on the climatic conditions of the region, the sanitary conditions of the reception basins and the storm water drainage network, the degree of dilution and mixing with groundwater, drain water and road washings, and the impact of technological production of industrial plants located in the catchment area or nearby [1]. In the northern regions and central Russia, surface water quality is largely formed under the influence of snow melting, which is typical for warm

\footnotetext{
* Corresponding author: GovorovaZhM@mgsu.ru
} 
winters and early spring, especially in the conditions of sharp fluctuations in air temperatures.

The main contaminants of the surface runoff from urban areas are suspended solids (SS), petroleum products (PP), COD, chlorides, etc. Furthermore, recently there has been a significant pollution of surface runoff with heavy metals, deicing and surface-active agents [1-10]. The dynamic of changes in concentrations of pollutants, especially SS and PP, correlates in most cases with the intensity of precipitation events of one of the most common types of rainfall. Table 1 shows the characteristics of rainfall runoff in some cities of Russia [1, 11, 12].

Table 1. Characteristics of rainfall runoff $(\mathrm{mg} / \mathrm{L})$ from urban areas

\begin{tabular}{|c|c|c|c|c|c|}
\hline Parameter & $\begin{array}{c}\text { Saint } \\
\text { Petersburg }\end{array}$ & Volgograd & Samara & Astrakhan & Perm \\
\hline $\mathrm{SS}$ & $50-1170$ & $420-1250$ & $50-1450$ & $215-281$ & $352-1100$ \\
\hline $\mathrm{pH}$ & $7.1-8.8$ & $7.41-7.8$ & $7-8$ & $8.6-9.4$ & $6.5-8.5$ \\
\hline $\mathrm{TDS}$ & $260-518$ & $444.5-5718$ & $471-891.6$ & - & $240-1190$ \\
\hline BOD5 & $20-50$ & $39.2-118.5$ & $5.2-316$ & - & - \\
\hline $\mathrm{COD}$ & $50-446$ & $200-280$ & & $57.6-195$ & $68-326$ \\
\hline $\mathrm{PP}$ & $7-12$ & $0,75-3$ & $0.125-475$ & $95-197$ & $0.46-9.93$ \\
\hline Sulfates & - & $126,8-216$ & $63.4-792$ & $195-212$ & $46-105$ \\
\hline $\mathrm{Chlorides}$ & $33-130$ & - & & $323-451$ & $92-850$ \\
\hline Ammonium-ion & $8-10$ & $0.45-2.08$ & $3.8-11.2$ & - & $0.4-1.0$ \\
\hline Phosphate & $0.5-0.8$ & - & $0.6-5.44$ & - & - \\
\hline $\mathrm{Fe}$ & $2-12$ & - & $0,03-10.7$ & - & $0.03-0.64$ \\
\hline $\mathrm{Zn}$ & - & 0.039 & $0-0.035$ & - & $0.02-0.08$ \\
\hline $\mathrm{Cu}$ & - & 0.22 & 0,058 & - & $0.09-0.26$ \\
\hline $\mathrm{Al}$ & - & - & $0-0.1$ & - & $0.07-0.45$ \\
\hline $\mathrm{Cr}$ & - & - & $0-0.5$ & $-003-0.04$ \\
\hline & - & -0.065 & - & $-15-0.27$ \\
\hline
\end{tabular}

Table 2 shows that the rainfall runoff contains dissolved mineral and undissolved organic impurities, as well as heavy metal salts, which concentration substantially depends on the type of urban area and the year season. The alkalinity of water ranges from 2 to 9 
$\mathrm{mEq} / \mathrm{L}$, and the total hardness - from 2.5 to $13 \mathrm{mg} / \mathrm{L}$. It is known that many substances in storm waters, including metals, toxic organic matter and pathogenic elements are attached to the surface of fine-dispersed particles of suspended solids. A similar pattern is observed in rainfall runoff from urban areas of foreign countries (Table 3).

Table 2. Changes in the concentration of heavy metals in the rainfall runoff by seasons [16]

\begin{tabular}{|c|c|c|c|}
\hline \multirow{2}{*}{ Types of urban territories } & \multicolumn{3}{|c|}{ Heavy-metal concentration (mg/L) } \\
\cline { 2 - 4 } & Winter & Spring & Summer \\
\hline Bus depots & 0.5 & 2.2 & 3.5 \\
\hline Residential area & 1.2 & 3.1 & 2.3 \\
\hline Fuel-filling stations & 4.8 & 4.3 & 3.0 \\
\hline Construction companies & 2.7 & 1.9 & 1.9 \\
\hline
\end{tabular}

Table 3. The composition of impurities of surface rainfall runoff $(\mathrm{mg} / \mathrm{L})[1,8,17]$.

\begin{tabular}{|c|c|c|c|c|}
\hline Parameter & $\begin{array}{c}\text { Munich } \\
\text { (Germany) }\end{array}$ & $\begin{array}{c}\text { Washington } \\
\text { (USA) }\end{array}$ & $\begin{array}{c}\text { Zhengzhou } \\
\text { City (China) }\end{array}$ & $\begin{array}{c}\text { Wuhan City } \\
\text { (China) }\end{array}$ \\
\hline SS & $165-15332$ & $130-11280$ & $489.5-2400.4$ & $40-1326.3$ \\
\hline TDS & $484-6374$ & $338-14600$ & - & - \\
\hline BOD5 & $6-609$ & $3-90$ & - & $56.7-279.2$ \\
\hline COD & $26-662$ & $29-1514$ & $150.2-1949.8$ & $50-116.5$ \\
\hline Total nitrogen & $1.1-6.2$ & $0.2-4.5$ & - & - \\
\hline pH & - & $6-7.2$ & - & - \\
\hline E.coli, thousans $/ \mathrm{m}^{3}$ & $2.4-99.1$ & $0.4-13$ & - & - \\
\hline
\end{tabular}

Russian Federation regulation imposes stringent requirements [13, 14] on the quality of treated surface wastewater, which determines the need for high degree of its purification before discharge into fishery water body.

The composition of treatment facilities and the technological scheme depends on the capacity, quality of surface wastewater from urban areas and the requirements for the degree of its purification. Conventional accumulative type treatment facilities usually include [15] mechanical purification using grids and sand traps, water clarification in accumulative settling tanks; removal of the bulk of organic and mineral contaminants using sedimentation, flotation or contact filtration with preliminary reagent treatment of wastewater; advanced treatment of residual mechanical impurities with petroleum products and organic matter sorbed on them using mechanical filtration on granular loads with standard flushing of filter bed; advanced treatment of wastewater using sorption to remove residual dissolved petroleum products and other organic compounds; disinfection of treated wastewater before it is discharged into water bodies or reused for service water supply. 
Although, biotechnology using such bioengineering facilities as biofiltration channels and slopes, biofields, phytofilters [18], are used in addition to the conventional technologies of surface runoff purification.

The specialists of the natural water purification and engineering water treatment facilities laboratory NRI VODGEO and research and development center «FONSVIT» developed four technological schemes for surface runoff purification (Table 4). Conceptual difference of the schemes is using accumulative clarifying tanks with the system of bottom by-passes, even distribution and collection of treated water and sludge removal, and different types of filters with floating polysterene load (Table 5) $[19,20]$. The use of filters with floating load can significantly reduce operational costs because it does not require flushing pumps and additional reservoirs for storing flushing water as filters with heavy load do.

Table 4. Technological schemes for surface runoff purification

\begin{tabular}{|c|c|c|c|c|}
\hline Scheme & $\begin{array}{c}\text { Capacity, } \\
\mathrm{m}^{3} / \mathrm{h}\end{array}$ & $\begin{array}{c}\mathrm{SS}, \\
\mathrm{mg} / \mathrm{L}\end{array}$ & $\begin{array}{c}\mathrm{PP}, \\
\mathrm{mg} / \mathrm{L}\end{array}$ & The composition of facilities \\
\hline I & $5-25$ & 700 & 40 & $\begin{array}{c}\text { Grid } \rightarrow \text { sand trap } \rightarrow \text { accumulative } \\
\text { reservoir } \rightarrow \text { hydrocyclone } \rightarrow \text { chemical feed } \\
\text { plant } \rightarrow \text { same to CPFZ } 1 \rightarrow \text { cartridge filters with } \\
\text { carbon fiber fabric from step I }\end{array}$ \\
\hline II & $25-500$ & 1000 & 40 & $\begin{array}{c}\text { Grid } \rightarrow \text { sand trap } \rightarrow \text { accumulative clarifying } \\
\text { tank } \rightarrow \text { hydrocyclone } \rightarrow \text { chemical feed plant } \rightarrow \text { filters } \\
\text { with hydraulic automatic flushing } \rightarrow \text { cartridge filters } \\
\text { with carbon fiber fabric from step I } \rightarrow \text { cartridge } \\
\text { filters with carbon fiber fabric from step II }\end{array}$ \\
\hline III & $500-1000$ & 700 & 20 & $\begin{array}{c}\text { Grid } \rightarrow \text { sand trap } \rightarrow \text { accumulative clarifying } \\
\text { tank } \rightarrow \text { hydrocyclone } \rightarrow \text { chemical feed } \\
\text { plant } \rightarrow \text { contact filter with floating load } \rightarrow \text { cartridge } \\
\text { filters with carbon fiber fabric from step } \\
\text { I } \rightarrow \text { cartridge filters with carbon fiber fabric from } \\
\text { step II }\end{array}$ \\
\hline IV & $1000-1500$ & 1000 & 40 & $\begin{array}{l}\text { Grid } \rightarrow \text { sand trap } \rightarrow \text { accumulative clarifying } \\
\text { tank } \rightarrow \text { hydrocyclone } \rightarrow \text { chemical feed } \\
\text { plant } \rightarrow \text { clarifying sorption filters } \rightarrow \text { cartridge filters } \\
\text { with carbon fiber fabric from step I } \rightarrow \text { cartridge } \\
\text { filters with carbon fiber fabric from step II }\end{array}$ \\
\hline
\end{tabular}

Table 5. Types of filters with floating polymer loading

\begin{tabular}{|c|c|}
\hline Name & Characteristic \\
\hline CFPZ-1, (FPZ-1) & Upward filtration through a heterogeneous loading layer \\
\hline AFPZ-4, FPZ-4 & $\begin{array}{c}\text { Downward filtration through a heterogeneous loading layer } \\
\text { (A - automatic flushing) }\end{array}$ \\
\hline CFPZ (CS) & $\begin{array}{c}\text { Two compartment filter. } \\
\text { Downward filtration through polystyrene load, followed by downward } \\
\text { filtration through a layer of sorption load }\end{array}$ \\
\hline
\end{tabular}

\section{Materials and methods}

A pilot plant (Fig. 1) was installed in the filtering chamber of the treatment facility to investigate the efficiency of surface runoff purification technology using filters with 
floating load. It included air separating tank; contact clarifying sorption filter CFPZ(CS) consisting of two model columns, loaded with granules of expanded polystyrene (FPZ-1) and sorbent (SF) respectively, cartridge filters of I and II step with activated carbon fiber fabric, a tank for a flocculant solution and a dosing pump. Pilot plant was equipped with process pipes, shutoff and control valves, samplers.

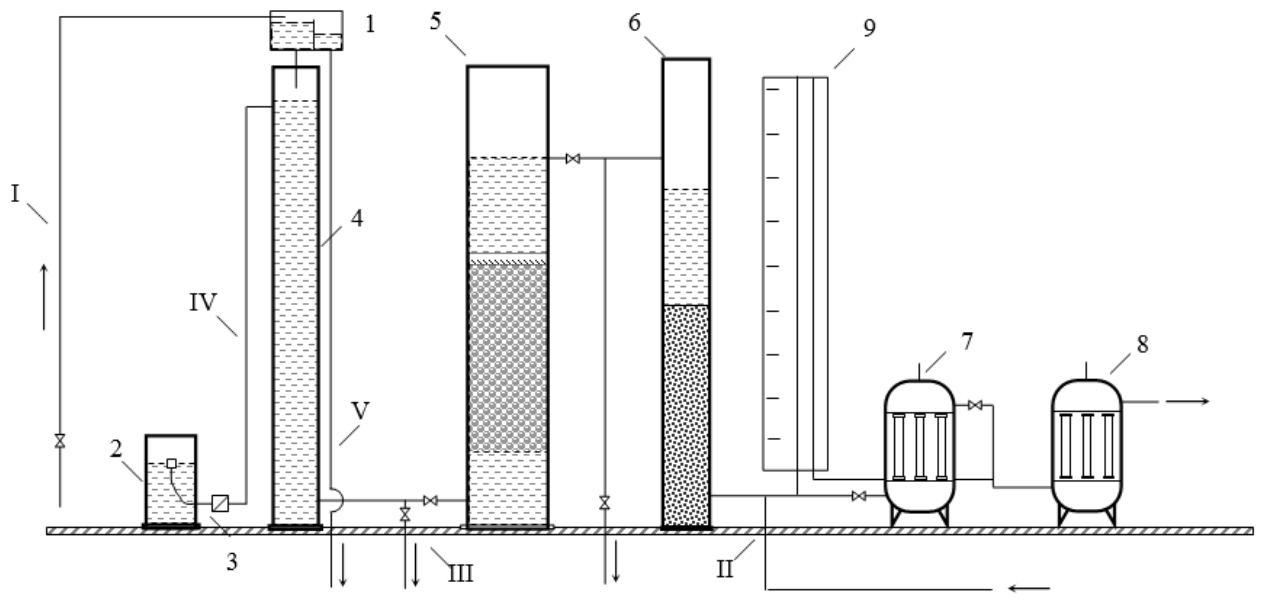

Fig. 1. Pilot plant scheme: 1 - constant head tank; 2 - tank for flocculant solution; 3 - dosing pump; 4 - air separating tank; 5 - clarifying filter; 6 - sorption filter; 7 - I step cartridge filter;

8 - II step cartridge filter; 9 - piezometer boar; I - source water supply; II - flush water supply; III - flush water discharge; IV - reagent line; V - overflow pipeline.

The filter load characteristics are given in (Table 6).

Table 6. Load characteristics.

\begin{tabular}{|c|c|c|c|}
\hline Filter & Material & Media size, $\mathbf{m m}$ & Layer thickness, $\mathbf{m}$ \\
\hline Clarifying (FPZ-1) & Polysterene & $1.5 \ldots 8$ & $1.2 \ldots 1.3$ \\
\hline Sorption (SF) & Activated carbon & $1 \ldots 2$ & $0.8 \ldots 1.0$ \\
\hline Cartridge (CF) & $\begin{array}{c}\text { Activated carbon fiber } \\
\text { fabric }\end{array}$ & - & - \\
\hline
\end{tabular}

The source water was supplied to the pilot plant via a pressure from the last section of industrial accumulative clarifying tank. During the investigation period the water after accumulative clarifying tank (ACT) had the concentration of SS - 81-180 mg/L, PP - 2-8 $\mathrm{mg} / \mathrm{L}, \mathrm{COD}-48-97 \mathrm{mg} / \mathrm{L}$.

Water filtration rate in clarifying filter was $5-6.5 \mathrm{~m} / \mathrm{h}$, sorption $-10-20 \mathrm{~m} / \mathrm{h}$. Crosssection area of I step cartridge filter $0.12-0.35 \mathrm{~m}^{2}$, II step $-0.12-0.8 \mathrm{~m}^{2}$. Polyelectrolyte VPK-402 and Praestol 650 TR/Praestol 853 BC flocculants were used with solution concentration of $0.0125 \%$ and $0.005-0.006 \%$ respectively. After each filter cycle, the polystyrene and sorption filters were flushed with water. Flushing intensity was 12-14 L/sec. $\mathrm{m}^{2}$, duration was 5-6 minutes.

The efficiency of the purification of surface runoff in the reagentless and reagent modes of water treatment at a pilot plant was studied. Treated water was sampled during the filter cycle at regular intervals of 2 hours. The amount of suspended solids was determined by the gravimetric method (PND F 14.1:2:4.254-2009). The mass concentration of petroleum 
products was determined by IR spectroscopy with pre-extraction of emulsified and dissolved petroleum products from water with carbon tetrachloride and its separation from the related organic compounds of other classes in a column filled aluminum oxide (PND F 14.1:2.116-97).

\section{Results}

During the investigation, the dynamic of changes in concentrations of suspended solids and petroleum products in previously treated in ACT water during the filter cycle, efficiency of water purification at each treatment step were studied, water filtration rates were refined. It has been experimentally established that without the use of reagents (coagulants, flocculants), even with decreasing the size of floating load granules, it is not possible to achieve the required degree of water purification by turbidity $(1-2 \mathrm{mg} / \mathrm{L})$ before sorption filters.

Cationic flocculants were used to intensify water purification by filtration. It allowed to cut the consumption of reagents, reduce the corrosivity of water, prevent secondary contamination of water with aluminum or iron ions, chlorides or sulphates. The flocculating activity of the reagents was determined by the method of trial coagulation. The dose of high-molecular cationic flocculants Praestol 853 TR and Praestol 650 TR in experiments varied from 0.5 to $1.2 \mathrm{mg} / \mathrm{L}$, and the dose of cationic flocculant Polyelectrolyte VPK-402 was $2-3.5 \mathrm{mg} / \mathrm{L}$.

The data presented in Fig. 2 and 3 show that the use of VPK-402 provides a sufficient reduction of suspended solids in filtered water from 120 to $15 \mathrm{mg} / \mathrm{L}$ and of petroleum products from 4.2 to $1.3 \mathrm{mg} / \mathrm{L}, \mathrm{COD}$ decreases from 58-97 to $20-23 \mathrm{mg} / \mathrm{L}$. Praestol $650 \mathrm{TR}$ showed the same efficiency but a greater increase of resistivity of filter load was observed.

It was experimentally established that the duration of the filtering cycle of the clarifying filter should not exceed 12 hours, and the filter rate in clarifying filter $-4.5-5 \mathrm{~m} / \mathrm{h}$, sorption filter - no more than $10 \mathrm{~m} / \mathrm{h}$, which allows to achieve a steady reduction of petroleum products in cartridge filters.

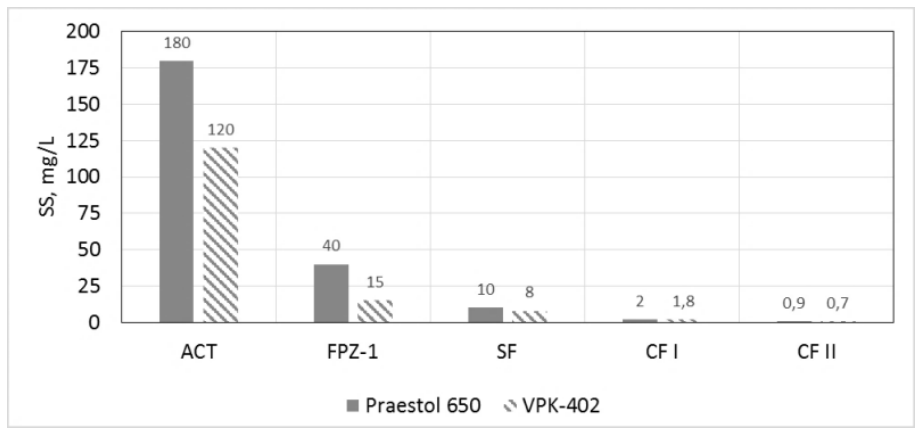

Fig. 2. Concentration of suspended solids in treated water 


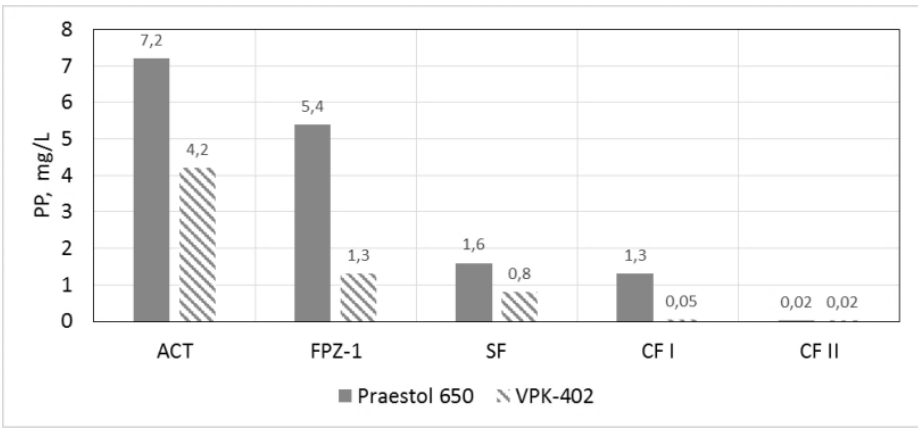

Fig. 3. Concentration of petroleum products in treated water

The research results were used to develop recommendations for intensifying the operation of industrial filters with floating and sorption loads as a part of surface runoff treatment facilities with a capacity of 2.5-30 thousand $\mathrm{m}^{3} /$ day (Fig. 4).

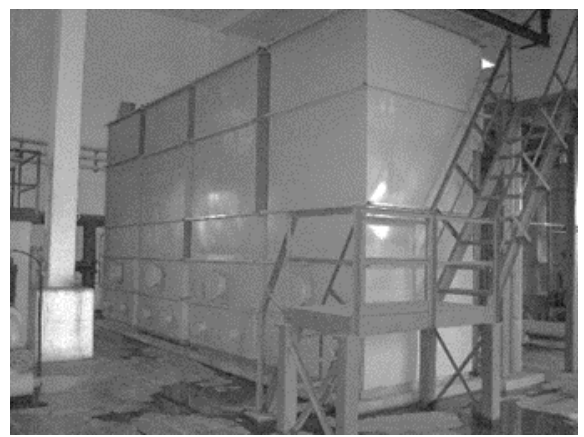

a)

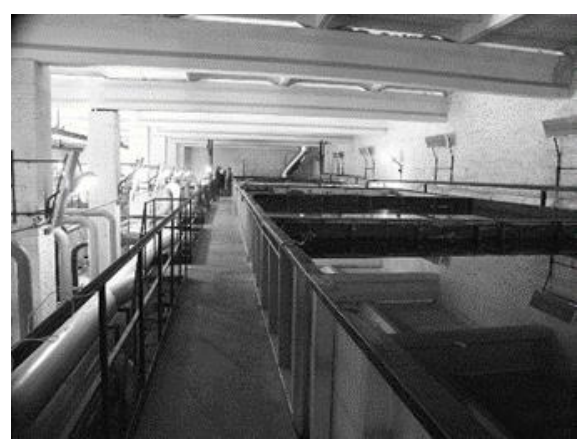

b)

Fig. 4. Surface runoff treatment facilities: a) - 20 thousand $\mathrm{m}^{3} / \mathrm{day}$, b) - 30 thousand $\mathrm{m}^{3} / \mathrm{day}$

\section{Conclusions}

Analysis of surface runoff water quality of various cities of Russia and foreign countries showed that the main contaminants are suspended solids, dissolved and undissolved organic compounds and, in some cases, heavy metal salts. There are stringent requirements for the degree of purification of surface runoff, which imposes requirements on the reliability of technology scheme and the composition of treatment facilities.

The efficiency of water purification process was experimentally studied at every stage of technological scheme. The operation parameters of the filter with a floating load were established. The investigation results showed that the reagent treatment of previously clarified in accumulative clarifying tank water followed by filtration through polystyrene load at 4,5-5 m/h filter rate and additional purification in sorption and I and II step cartridge filters for 12 hours guarantees the required degree of purification of surface runoff before discharge into a water body. The investigation results were the basis for the development of recommendations for the intensification of operation and improving the technological reliability of Moscow industrial surface runoff treatment facilities. 


\section{References}

1. M.A. Alekseyev, A.M. Kurganov, Organizatsiya otvedeniya poverkhnostnogo (dozhdevogo i talogo stoka) s urbanizirovannymi territoriyami (Publishing Association of Construction Universities, 2000)

2. E.D. Palagin, A.K. Strelkov, P.G. Bykova, A.V. Tsypin, D.V. Vdovin, Vodosn. i san. tekhnika, 12, 41-46 (2016)

3. E.D. Palagin, M.A. Gridneva, P.G. Bykova, A.A. Pavlukhin, Vodosn. i san. tekhnika, 12, 28-35 (2018)

4. L.P. Alekseyeva, Vodosn. i san. tekhnika, 9, 27-34 (2009) G. Ignatavičius, V. Valskys, I. Bulskaya, D. Paliulis, A. Zigmontienè, J. Satkūnas, Estonian J. of Earth Sciences, 66/1, 13-20 (2017)

5. R. Buzier, M.H. Tusseau-Vuillemin, M. Keirsbulck, J.M. Mouchel, Physics and Chemistry of the Earth, 36, 500-505 (2011)

6. S. Marshall, V. Pettigrove, M. Carew, A. Hoffmann, Envir. Pollut., 158, 1716-1725 (2010)

7. M. Scholz, S. Kazemi Yazdi, Water Air Soil. Pollut., 198, 55-64 (2009)

8. M. Zhang, H. Chen, J. Wang, G. Pan, J. of Envir. Sciences, 22/1, 40-46 (2010)

9. R.H. Kim, S. Lee, Y.M. Kim, J.H. Lee, S.K. Kim, S.G. Kim, Envir. Technology, 26, 411-420 (2005)

10. J.W. Zhao, B.Q. Shan, C.Q. Yin,Techniques and Equipment for Envir. Pollut. Control, 7/12,14-17 (2006)

11. V.I. Kichigin, P.G. Bykova, Vodosn. i san. Tekhnika, 11, 28-32 (2002)

12.I.S. Schukin, A.G. Melekhin, Vestnik of Perm National Research Polytechnic University, 4(8), 110-118 (2012)

13. Water Code Of The Russian Federation (Eksmo, 2016)

14. SanPiN (Sanitary Rules and Regulations) 2.1.5.980-00. Hygienic requirements for surface water protection (Morkniga, 2017)

15. Rekomendatsii po raschetu sistem sbora, otvedeniya i ochistki poverkhnostnogo stoka s selitebnykh territoriy, ploshchadok predpriyatiy i opredeleniyu usloviy vypuska yego $v$ vodnyye ob"yekty (NRI VODGEO, 2014)

16. O. Primin, G. Varyushina, A. Ten, (2018). Available at: https://www.matecconferences.org/articles/matecconf/pdf/2018/110/matecconf_ipicse2018 03050.pdf

17. L.Q. Li, C.Q. Yin, L.L. Kong, Q.C. He, Environ. Science, 28/10, 7822-7828 (2007)

18. O. Ruchkinova, I. Shchuckin, (2017). Available at: https://iopscience.iop.org/article/10.1088/1755-1315/72/1/012002/pdf

19. M.G. Zhurba, Vodoochistnyye fil'try s plavayushchey zagruzkoy (Floating-water treatment filters) (Moscow, 2011)

20.Zh.M. Govorova Regulation and purification of surface sewage (VNIINTPI, 2005) 